\title{
A retrospective study of ilizarov fixation in infected non-union tibia: 36 cases
}

\author{
Rajesh Govindasamy ${ }^{1}$, Ramkumar Gnanasundaram², Saravanan Kasirajan ${ }^{1}$, \\ Jimmy J Meleppuram, Pajani Sengani ${ }^{1}$
}

\author{
${ }^{1}$ Department of Orthopaedics, Vinayaka Missions Medical College (V.M.M.C) Karaikal, Puducherry, India \\ ${ }^{2}$ Department of Orthopaedics, Saveetha Medical College, Chennai, India
}

Received: 20 July 2016

Accepted: 26 July 2016

\author{
*Correspondence: \\ Dr. Rajesh Govindasamy, \\ E-mail: drgrortho@yahoo.com
}

Copyright: (c) the author(s), publisher and licensee Medip Academy. This is an open-access article distributed under the terms of the Creative Commons Attribution Non-Commercial License, which permits unrestricted non-commercial use, distribution, and reproduction in any medium, provided the original work is properly cited.

\section{ABSTRACT}

Background: Infected non-union of tibia is most frequently met due to high energy trauma and it poses significant challenge to the treating orthopaedic surgeon. The aim of the study is to evaluate the clinical and functional results in treating infected non-union of tibia by Ilizarov method.

Methods: 36 patients with infected non-union of tibia with bone loss; shortening and deformity treated were retrospectively analyzed in the institution during the period of May 2010 to May 2015 were included in the study. The results were evaluated according to association for the study and application of the methods of Ilizarov (ASAMI) criteria. The Pin tract infections were assessed by Moore and Dahl Grading.

Results: The bony results were excellent in $65 \%$ patients, good in $20 \%$, fair in $15 \%$, and poor in nil. The functional results were excellent in $50 \%$ patients, good in $25 \%$, fair in $15 \%$, and poor in $10 \%$. The most common recorded complication was pin tract infection.

Conclusions: Ilizarov ring fixator still remains an excellent treatment modality for tibial non-union as it addresses to the problems associated with it.

Keywords: Tibia, Ilizarov technique, Nonunion, Infection

\section{INTRODUCTION}

Tibia, as a subcutaneous bone is vulnerable to trauma and its fractures are common which are mostly open and complex among the long bone fractures. Delayed unions, non-union with associated infections are relatively common complications. The non-union ranges from 2 to $10 \%$ of all tibia fractures. Treating infected non-union of tibia is one of the perplexing dilemmas in orthopaedic surgery because of its delayed treatment after a high energy trauma, as it has a thin soft tissue envelope with poor blood supply and complex fracture patterns and results usually has an unfavourable outcome.
After multiple surgeries with huge burden of cost and prolonged period of immobilization makes patient life miserable, and the end results are not satisfactory and amputation may still be the outcome. To eradicate infection and to establish bony union with a good functional extremity often requires a courageous measure. The treatment of infected non-union of tibia by distraction osteosynthesis by ilizarov method can also address a coinciding deformity, shortening, bone loss or infection. ${ }^{1}$

According to Ilizarov, to eliminate infection and obtain union, vascularity must be increased. In this technique, vascularity is increased by corticotomy and application of 
a circular external fixator. It also provides micro motion due to distraction and gives an excellent biological environment for fracture healing. ${ }^{2}$ Ilizarov technique has the additional advantage of efficient fixation which allows early mobilization and maintains articular function, eliminates the need for bone grafting and has minimal complications. ${ }^{3}$

In present study, the role of ilizarov fixation in infected non union of tibia was evaluated, we looked for union, infection, function and to know the complications associated with it.

\section{METHODS}

Thirty six patients with infected non-union of tibia for more than six months treated by ilizarov fixation method from May 2010 to May 2015 were retrospectively analyzed. There were seven females $(19.4 \%)$ and twenty nine males $(80.6 \%)$ with an average age of 37 years (range, 20 to 60 years) at the initial operation. Majority were manual labourers and injuries were caused by road traffic accidents $(n=32)$ and by fall $(n=4)$. The right side was included in twenty cases $(55.6 \%)$ and the left side in sixteen cases $(44.4 \%)$. Infected non-union was classified by G. S. Kulkarni classification (Table 1). 3 Infected nonunion of lower one third tibia constituted most cases in our study.

Table 1: G.S. Kulkarni's classification for non-union.

\begin{tabular}{|cl|}
\hline Type I & $\begin{array}{l}\text { Fragments in apposition with mild } \\
\text { infection and with or without } \\
\text { implant }\end{array}$ \\
\hline Type II & $\begin{array}{l}\text { Fragments in apposition with severe } \\
\text { infection with large or small wound }\end{array}$ \\
\hline Type III & $\begin{array}{l}\text { Severe infection with a gap or } \\
\text { deformity or shortening }\end{array}$ \\
IIIa & $\begin{array}{l}\text { Defect with loss of full circumference } \\
\text { IIIb }\end{array}$ \\
IIIc & Infected in $>1 / 3^{\text {rd }}$ of cortex \\
\hline
\end{tabular}

\section{Inclusion criteria}

\section{All infected non-union of tibia associated with}

- Bone loss $<10 \mathrm{~cm}$.

- Varying degree of limb shortening and deformity.

\section{Exclusion criteria}

- Congenital pseudoarthrosis of tibia.

- Non union tibia not associated with infection.

- Infected fractures less than 6 months .

- Fresh compound fractures.

- Ipsilateral non union femur.

\section{Surgical technique}

Depending on initial clinical assessment and radiographs, appropriate ilizarov frame was assembled prior to surgery. Oblique incision was preferred to avoid wound closure problems. Initial metal work if present was removed and in patients who had previous intramedullary nail, tibia was reamed. The bone ends were debrided and samples were taken for microbiology and histopathology. Both ends of the bone if needed were kept in alignment with plate and screws temporarily and then frame was applied with trans-osseus wires and half pins to preserve the anatomical axis and avoid any additional soft tissue damage. If needed the frames were extended to the foot to minimize equinus deformity whenever necessary. Tourniquet was used until debridement and freshening of the edges and wires introduced after removal of tourniquet and wires were tensioned up to $110 \mathrm{kgs}$. If soft tissue coverage was required then this was done by plastic surgeons at the same sitting. Corticotomy was performed as second stage procedure in needed cases by wires using DE BESTIANI technique. ${ }^{4}$ Whenever union is delayed, we augmented non-union site with bone marrow injection or bone grafting.

Post operatively patient was on intravenous antibiotics and analgesics for a week with leg positioned over the pillow so that knee kept extended all the times, passive dorsiflexion splints for the ankle given. To stimulate early bone healing immediate weight bearing was encouraged in most cases, intensive physiotherapy to maintain or to regain normal range of motion of the knee and ankle joints was considered an important part of the treatment.

After surgery there was no changes for seven days; thereafter all manipulations were done by the patients themselves by turning nuts on the fixator of the apparatus four times a day, resulting in movement in the axis of the bone of one $\mathrm{mm}$ per day. In cases requiring internal bone transport, the bone segment between the non-union corticotomy site was moved distally and the bone segment reached the former non-union site eventually followed by docking.

Consequently we assessed patients every two weeks clinically for pin site infections, stability of frame and radiological assessment was done every four weeks for union at the non-union site and consolidation of the regenerate. Fixator was removed when the regenerate consolidated and the non-union was corticolised on three of four sides as seen on the anteroposterior and lateral $\mathrm{x}$ rays. ${ }^{5,6}$ We used protective casts for an additional two months because of our fear of refracture in all our cases.

\section{RESULTS}

In our study of 36 patients, no patients were lost during follow up. At follow up examination 15 months (range 10 to 42 months) after frame removal the final outcome was 
evaluated by criteria laid down by association for the study and application of the methods of Ilizarov (ASAMI) for bone and functional results. ${ }^{7}$ In majority of the cases external fixator held for a time period of 9-11 months. Bone loss after initial debridement was $2-5 \mathrm{~cm}$ in most of our cases.

In our study, $85 \%$ of the patients were treated by bifocal osteosynthesis that is acute docking of the non-union site followed by corticotomy and distraction at other site. Limb length discrepancy was assessed at the end of treatment after union. In $30 \%$ of cases there was no limb length discrepancy after treatment. In most cases the limb length discrepancy was $0.5-1.5 \mathrm{~cm}$.

In terms of organism, 24 patients grew staphylococcus aureus, five patients grew pseudomonas, three patients grew coagulation negative staph, one grew streptococcus viridans and propionibacterium each, and two patients had negative culture as they were on antibiotics preoperatively.

Bone results were assessed by ASAMI scoring. An excellent bone result was one that had no evidence of infection, a deformity of 5 degree or less in any one plane, an limb length discrepancy (LLD) less than $2.5 \mathrm{~cm}$ and a bone union wide enough not to require long term bracing or protection.7 In our study, we had excellent results in $65 \%$ of cases $(n=23)$, all thirty-six patients had successful union after ilizarov bone transport at the end of one year, and none required amputation.

Functional results were assessed by ASAMI scoring. An excellent functional result was one in which the patient had no pain or mild pain (not requiring narcotics), did not require a walking aid or brace, did not have joint contracture greater than 5 degree, did not lose more than 20 degree of ankle motion, and was able to perform all activities of daily living. ${ }^{7}$ In our study, functional results were excellent in $50 \%(n=18)$ of cases.

Complications were sub classified according to paley in "problems" solved during treatment without operative intervention, "obstacles" that requires an operative intervention and true "complications" that were not resolved before the end of treatment. ${ }^{8}$ The true complications were considered minor if they did not interfere with achieving the original goal. We recorded 34 problems in 36 patients; the problems consisted mainly of pin tract problems of which 28 patients with pin site inflammation which subsided with regular dressings and oral antibiotics. Four patients with pin site soft tissue infection were resolved by intravenous antibiotics (Figure 1). Two patient had transient paresthesia which resolved by itself.

We recorded 20 obstacles in 15 patients. Six patients required one additional procedure each. Three patients required two additional procedures each. One required three additional procedures. Additional procedures included revision for drifting transport fragment $(n=4)$, debridement and grafting at docking site $(n=11)$, repeat osteotomy $(n=2)$, iliac bone graft to regenerate $(n=2)$, and foot plate addition for equinus contracture $(n=1)$. There were no major complications in our study.

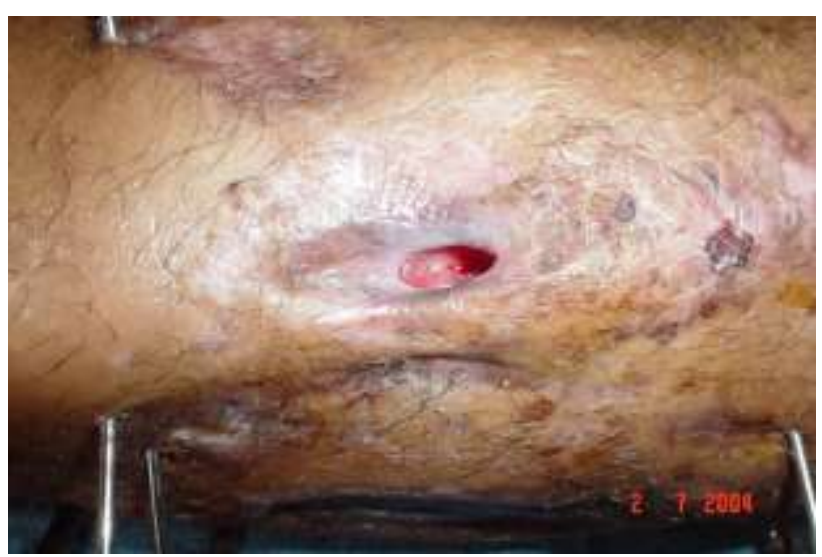

Figure 1: Grade 4 pin site infection according to Moore and Dahl classification.

\section{DISCUSSION}

The ilizarov technique offers an effective and reliable treatment for some of the most challenging conditions in orthopaedic practice such as infected tibial non unions. It was initially developed in kurgan, Russia in 1950 by Gavril A Ilizarov. Infected tibial non unions are a complicated problem requiring complex time consuming surgery. Our study has demonstrated, good function can be achieved in terms of union, infection, pain relief and activities of daily living. Present study, using ASAMI criteria, where on par with other studies.

A diagnosis of non-union can be made when at least 6 months have elapsed with no evidence of progression of healing after the time of fracture, at this point, if there is an infection then it tends to be chronic and organism tends to be resistant to most antibiotics. ${ }^{9,10}$ Radical wound debridement with all necrotic bone should be completely resected together with problems like leg length discrepancy, deformity, joint stiffness; diffuse osteoporosis should be addressed. ${ }^{11}$ In our study $100 \%$ eradication of infection was noted which is comparable to other studies. ${ }^{11,12}$ Though ilizarov had not used antibiotics, we have used both oral and intravenous antibiotics depending upon the culture report for 4-5 weeks.

In our study duration of external fixation was 9-11 months in most cases which is comparable to other studies. ${ }^{13}$ In our study we noted bone lengthening index i.e. duration required for formation of $1 \mathrm{~cm}$ of new bone was 1.48. Studies has shown smoking has a poor statically outcome on duration of external fixator and bone lengthening index. ${ }^{14}$ Our patients were strictly advised to stop smoking during the course of treatment. 


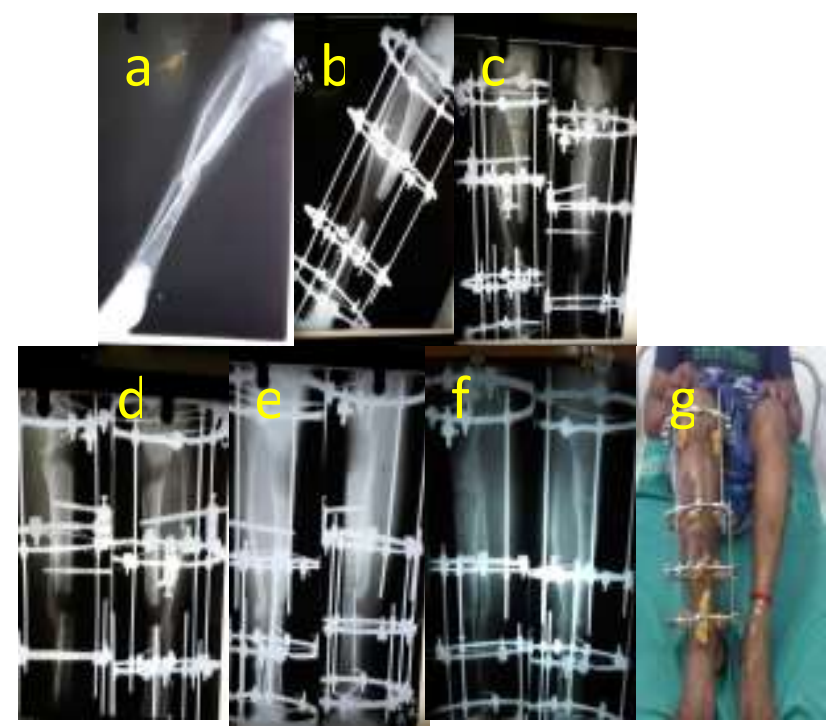

Figure 2: a) 32 year old male with infected non-union right tibia type IIIc of kulkarni's classification b) Post-op Xray showing radical debridement and preliminary ilizarov ring fixation c) $X$-ray showing post corticotomy status d,e) X-ray showing bone transport f) fracture united g) ilizarov fixator insitu after 7 months of union with excellent union and excellent functional outcome.

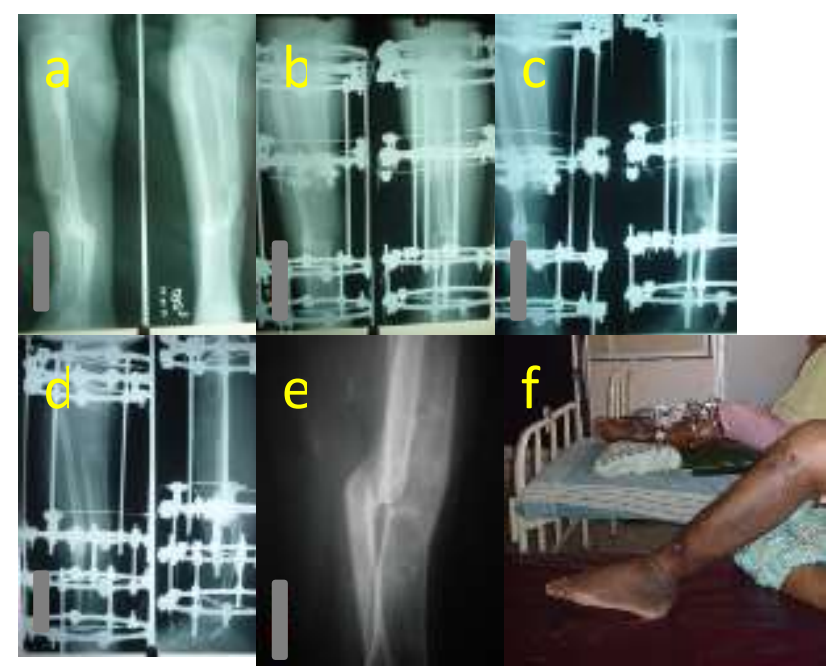

Figure 3: a) A 30 year old male with infected nonunion left tibia type IIc of Kulkarni's classification b) Immediate post-op $x$-ray showing radical debridement and preliminary ilizarov ring fixation c) one month X-ray showing corticotomy done d) X-ray

showing ongoing bone transport and docking e) United fracture with Ilizarov ring removed f) Ilizarov fixator removed after 8 months of union with excellent union and good functional outcome.

In our study, bone results were excellent in $65 \%$ of cases (Figure 2), good in $20 \%$ of cases (Figure 3), fair in $15 \%$ of cases and didn't have any poor results making it superior to other studies (Table 2). In our current study though bone results were better than functional results. It shows excellent bone does not guarantee good function. The functional result is affected by the soft tissue and neurovascular structures. 8 Our functional results were better as compared to other studies (Table 3 ).

Table 2: Bony results comparison.

\begin{tabular}{|lllll|}
\hline Results & Excellent & Good & Fair & Poor \\
\hline Dror Paley et al $^{16}$ & $60.87 \%$ & $26.09 \%$ & $8.7 \%$ & $4.35 \%$ \\
\hline $\begin{array}{l}\text { Madhusudhan et } \\
\text { al }^{17}\end{array}$ & $22 \%$ & $36.34 \%$ & $22 \%$ & $18.18 \%$ \\
\hline Dendrinos et al $^{18}$ & $50 \%$ & $29 \%$ & $3.6 \%$ & $17.4 \%$ \\
\hline Lalit Maini et al $^{19}$ & $70 \%$ & $10 \%$ & $0 \%$ & $20 \%$ \\
\hline Present study & $65 \%$ & $20 \%$ & $15 \%$ & $0 \%$ \\
\hline
\end{tabular}

Table 3: Functional results comparison.

\begin{tabular}{|lllll|}
\hline Results & Excellent & Good & Fair & Poor \\
\hline Dror Paley et al & $64 \%$ & $28 \%$ & $4 \%$ & $4 \%$ \\
\hline $\begin{array}{l}\text { Madhusudhan } \\
\text { et al }\end{array}$ & $5.56 \%$ & $22.22 \%$ & $33.33 \%$ & $38.89 \%$ \\
\hline Dendrinos et al & $25 \%$ & $39.2 \%$ & $14.3 \%$ & $2.15 \%$ \\
\hline Lalit Maini et al & $26.7 \%$ & $40 \%$ & $10 \%$ & $28.3 \%$ \\
\hline Present study & $50 \%$ & $25 \%$ & $15 \%$ & $10 \%$ \\
\hline
\end{tabular}

In our study, of 36 patients we had 45 complications at the rate of 1.4 complications per patient which was comparable to other studies. In that, there were 34 problems and 15 obstacles, among 34 problems 32 were due to pin tract infections assessed by Moore and Dahl grading (Table 4). Among which 20 patients had grade II infection, ten patients had grade III infection and two had grade IV infection for which the pin was removed and reapplied. The high rate of pin tract infection was due to low socio economical status and residing at villages where facilities for regular dressing were also less. Soft tissue complications including wound breakdown, invagination and significant joint contractures were not very common in our study as compared to other studies. We also found that multidisciplinary approach was very much helpful to our successful outcomes.

Table 4: Moore and Dahl pin site classification.

\begin{tabular}{|ll|}
\hline Grade & Inflammation \\
\hline 0 & None or Marginal \\
\hline 1 & Marginal inflammation \\
\hline 2 & Inflamed-Serous \\
\hline 3 & Inflamed-Purulent \\
\hline 4 & Inflamed with induration-Seropurulent \\
\hline 5 & Inflamed with induration, tenderness, \\
& surrounding erythema-gross purulent \\
\hline
\end{tabular}

Overall ilizarov bone transport is an effective salvage tool in obtaining union in patients with an infected non-union associated with bone loss. The lengthy treatment time and considerable number of complications must be fully understood both by the surgeon and the patient before 
undertaking this unique treatment process. In order to obtain faster union rate patient should be a non-smoker and smokers should be strictly advised cessation of smoking. This technique also gives better results in concern to bone healing and also gives an opportunity for correction of deformities and shortening at the same time. ${ }^{15}$

\section{ACKNOWLEDGEMENTS}

Authors would like to thank patients for their cooperation in the study and thank Meleppuram J.J. for manuscript preparation and Sengani P. for collecting data. All authors read and approved final manuscript.

Funding: No funding sources

Conflict of interest: None declared

Ethical approval: Not required

\section{REFERENCES}

1. Aronson J, Johnson E, Harp JH. Local bone transportation for treatment of intercalary defects by the Ilizarov technique. Biomechanical and clinical considerations. Clin Orthop Relat Res. 1989;(243):71-9.

2. Ilizarov GA. The tension-stress effect on the genesis and growth of tissues. Part I. The influence of stability of fixation and soft-tissue preservation. Clin Orthop Relat Res. 1989;(238):249-81.

3. Marsh DR, Shah S, Elliott J, Kurdy N. The Ilizarov method in nonunion, malunion and infection of fractures. J Bone Joint Surg Br. 1997;79(2):273-9.

4. De BG, Aldegheri R, Renzi BL, Trivella G. Limb lengthening by callus distraction (callotasis). J Pediatr Orthop. 1987;7(2):129-34.

5. Maffulli N, Lombari C, Matarazzo L, Nele U, Pagnotta G, Fixsen JA. A review of 240 patients undergoing distraction osteogenesis for congenital post-traumatic or postinfective lower limb length discrepancy. J Am Coll Surg. 1996;182(5):394-402.

6. Paley D. Current techniques of limb lengthening. J Pediatr Orthop. 1988;8(1):73-92.

7. Paley D, Maar DC. Ilizarov bone transport treatment for tibial defects. J Orthop Trauma. 2000;14(2):7685.

8. Paley D. Problems, obstacles, and complications of limb lengthening by the Ilizarov technique. Clin Orthop Relat Res. 1990;250:81-104.
9. Towers AG. Wound infection in an orthopaedic hospital. Lancet. 1965;2(7408):379-81.

10. Gristina AG, Naylor PT, Myrvik QN. Mechanisms of musculoskeletal sepsis. Orthop Clin North Am. 1991;22(3):363-71.

11. Dendrinos GK, Kontos S, Lyritsis E. Use of the Ilizarov technique for treatment of non-union of the tibia associated with infection. J Bone Joint Surg Am. 1995;77(6):835-46.

12. García CE, Martí GJC. Circular external fixation in tibial nonunions. Clin Orthop Relat Res. 2004;419:65-70.

13. Sen C, Eralp L, Gunes T, Erdem M, Ozden VE, Kocaoglu M. An alternative method for the treatment of nonunion of the tibia with bone loss. J Bone Joint Surg Br. 2006;88(6):783-9.

14. Mc Kee, Dipasquale DJ, Wild LM, Stephen DJ, Kreder HJ, Schemitsch EH. The effect of smoking on clinical outcome and complication rates following Ilizarov reconstruction. J Orthop Trauma. 2003;17(10):663-7.

15. Paley D, Catagni MA, Argnani F, Villa A, Benedetti GB, Cattaneo R. Ilizarov treatment of tibial nonunions with bone loss. Clin Orthop Relat Res. 1989;(241):146-65.

16. Paley FB, Chirstianson D. An analysis of Illizarov and external fixators. Clin Orthop Relat Res. 1989;241:195.

17. Madhusudhan RT, Balasundaram R, Manjunath KS, Harshad MS, Dabir CS, Krishnappa N. Outcomes of Ilizarov ring fixation in recalcitrant infected tibial non-unions-a prospective study. J Trauma Management Outcomes. 2008;2(6):1-9.

18. Dendrinos GK, Kontos S, Lyritsis E. Use of the Ilizarov technique for the treatment of non-union of the tibia associated with infection. J Bone Joint Surg Am. 1995;77:835-46.

19. Lalit M, Chadha M, Vishwanath J, Kapoor S, Mehtani A, Dhaon BK. The Ilizarov method in infected nonunion of fractures. Injury. 2000;31(7):509-17.

Cite this article as: Govindasamy R, Gnanasundaram R, Kasirajan S, Meleppuram JJ, Sengani P. A retrospective study of ilizarov fixation in infected nonunion tibia: 36 cases. Int J Res Orthop 2016;2:70-4. 